\title{
Evaluation Framework of Human Resource Management Effectiveness in Organizations
}

\author{
Deepa Sharma, S. Ramachandran, Mandeep Kaur
}

\begin{abstract}
Human Resource Management (HRM) Play a vital role in today era.HRM Evaluation based on what they do for the Companies that employ them and how they relate to those on the Organization operation side. Human Resource Management takes the decisions for the Organization's beneficial if the Organization gain the profit that means HRM takes the effective and accurate decisions in favor of Organization's.HRM are the decisions makers like the Operating function, information and Finance decisions etc. Human Resource Management that role changed with the advent of the technological age. HRM is a play very vital role between employees and management. In other words we can say that Organizations are not mere bricks, mortar, machineries or inventories. .HRM refers to core person of the organization HRM department take the effective decisions in favor of employees and organizations. .HRM takes the effective decisions on the behalf of the organizations.
\end{abstract}

Index Terms : Human Resource Management, Strategic Management

\section{INTRODUCTION}

HRM evaluation refers to the how to organization achieved the goals and objectives through the minimum cost on maximize the profit. Success of organization depend on the decisions taken by the Human Resource Management .Through the HRM help the company achieved the strategic objectives .HRM evaluations success depends on recruit and select of employees appoint on Right person on Right Place, then provides training of employees and effective outcomes get the organization's. HRM not only makes the plans also give the framework of plan to implementing the plan. Time to time to check the performance of employees which employees need the training program. All the factors who affected the organization's motives to be controlled by the Human Resources Management. Change is the part of our life if any Organizations changed happened in the organization for example technological change, controlled by their. In any tasks performed by employees to time to time check out to provide guidelines how to performed the particular task. HRM provides an analytical framework for studying how to retain the employees in the organization. To hiring the people according to requirement of job, to describe the employees what's responsibilities of assign job, what's rules and regulation of the organizations. Clearly define the objectives of organization to individuals and the work team shall be the

Revised Manuscript Received on July 5, 2019.

Ms. Deepa Sharma, MMIM, Maharishi Markendeshwar deemed to be University, Mullana, Ambala, India, deepasharma36099@gmail.com

Dr.S.Ramachandran, Maharishi Markendeshwar deemed to be University, Mullana, Ambala, India.

Ms. Mandeep Kaur, Maharishi Markendeshwar deemed to be University, Mullana, and Ambala, India. cornerstone of our activities. Ethically do the work in the organization, equal opportunities provide to an employee.

\section{FACTOR AFFECTING HRM EFFECTIVENESS IN ORGANIZATIONS}

Every organization main motive to gaining the profit. Various factors affecting the Organizations profits and HRM effectiveness shown in the following figure 1.1

Factors Affecting HRM Effectiveness in Organization's

\begin{tabular}{|l}
$\checkmark$ Education \\
$\checkmark$ Culture \\
$\checkmark$ Economic System \\
$\checkmark$ Political \\
\hline
\end{tabular}

A. Education-If human resource management takes the decisions to using own skills, knowledge or abilities as result organizations achieved the profits we evaluate the HRM effectiveness.

B. Culture-Culture is also main factor because every organization's culture is vary to vary one organization to another organization.

C. Economic System- Economic system that means to analyses the production, distribution and consumption of goods and services.

\section{MEASURES THE EVALUATION OF HRM EFFECTIVENES}

HRM is a core element of any organization. Decisions should be taken by HRM made must influences the effectiveness of an organization. HRM fully concentrate of every activities of the organization like how to be accomplishments of firm's goals to full utilization of resources on minimum cost Strongly identifies the Organization's Strength and Weakness. To promote the employees to appraisal the employees performance. 
Human Resource Management makes the policies in favor of organization's to encourage the individuals employees and group of peoples to do the work in team and gives effective results to organizations. HRM effectiveness shown following model given below

\section{Individual Employees Performance Indicators-:}

Absenteeism

Accidents

Separations

Group Performance Indicators-:

Interpersonal Relations

Dynamics Processes

\section{HRM-:}

Policies

Principles

Practical's Systems

Organizational Performance Indicators-:

Quality

Costs

Productivity

Individual employee's performance Indicators-: HRM totally focuses on individual employees who done the work in the organization. To evaluate the employees performance to promote them. Absenteeism.

Accidents- If within organization any Accidents happen in the organization to HRM provides them compensation amount.

Absenteeism- In a month employees take the holiday or absent from the organization to maintain the records regarding absenteeism.

Separations-Mostly HRM focuses on how to reduce the turnover rate of employees and retain the employees in the organization.

\section{HRM}

Policies- HRM make the policies in favor of organizations and not only make policies, implement also.

Principles- HRM principles are clear like to minimize the cost and maximized the profits and provide the high quality product to customers on reasonable prices.

Practical's- Polices makes by HRM not only in written form, as well as practically implement in the organizations.

Systems- HRM functions based on systematic, firstly hiring, selects, training and performance appraisal done etc.

\section{INDIVIDUAL EMPLOYEE'S PERFORMANCE INDICATOR}

HRM totally focuses on individual employees who done the work in the organization. To evaluate the employees performance to promote them. Absenteeism.

A.Accidents - If within organization any Accidents happen in the organization to HRM provides them compensation amount.

B.Absenteeism- In a month employees take the holiday or absent from the organization to maintain the records regarding absenteeism.
C.Separations-Mostly HRM focuses on how to reduce the turnover rate of employees and retain the employees in the organization.

\section{ORGANIZATION PERFORMANCE INDICATOR}

A.Costs- Every organizations main objective to profit earning so HRM reduce the cost of product at manufacring time, reduce the wastage and full utilization of resources at minimum cost.

B.Quality-To provide the customer quality products and services on reasonable price.

C.Productivity- Operations function should be understood by employees to produce the goods without wastage and effective manner.

\section{CONCLUSION}

HRM Play a very vital role in every organizations because HRM helps the organizations to achieved the organizational goals and objectives through the HR functions like Recruitment, Selection, Training and Development ,Retain the employees in the organization's .To make the policies ,systems based on the evidence.HRM follow the sequence ,timely motivate the employees individually and team and technical work in the form of a systematic gathering and analysis of data .In the last we can say that HRM evaluation through the organizational profits, goodwill, and market share captured by the organizations. Through the HRM easily personal , Functional and Organizational objectives.

\section{REFERENCES}

1. Aswathappa,k; Human Resource Management ,Himalaya Publishing House, Bombay 1990, p.626

2. www.questia.com-HRM articles, Research studies

3. www.hrmguide.net-HumanResourceManagement

4. International Studies of Management and Organization, 30(1), 63-92.

5. Anderson, S. (2004). Internationalization in different industrial contexts. Journal of Business Venturing, 19, 851-875. An, P., and Qiao.B., (2008).

6. Askewer, K. (1996). External-internal linkages and overseas autonomy-control tension: the management.

\section{AUTHORS PROFILE}

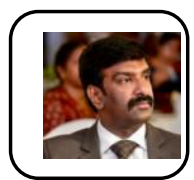

Dr. S. Ramachandran, Dean Faculty of MMIM Maharishi Markandeshwar deemed to be University, Mullana PhD Marketing Management, University of Madras; Graduate in Chemistry with MBA in Marketing Management, University of Madras. Book published 1 Marketing Management- Ruby Publishers- ISBN No. 978-93-80430-40-62. Ports and Shipping Management- AMET PublishersISBN No. 978-81-926045-3-43. Global Maritime Business- AMET Publishers- ISBN No. 978-81-926045-4-14. Warehousing and Allied Management- AMET Publishers- ISBN No. 878-81-926045-7-2 
Ms. Deepa Sharma PhD Research Scholar, MMIM, Maharishi Markendeshwar deemed to be University, Mullana, 4 years experience as a assistant professor in KIT, 4 years teaching experience. She has

Interested area Human Resource Management and

marketing.

Ms. Mandeep Kaur, PhD Research Scholar, MMIM, Maharishi Markendeshwar deemed to be University, Mullana, 2 years experience in A.G. Financial Services, 2 years teaching experience. 